\title{
Por trás do artigo de Química*
}

\author{
R. HOFFMANN*
}

Se abrir um número duma revista moderna de Química, como a conceituada Angewandte Chemie alemã, [1] ou 0 Journal of the American Chemical Society, o que vê? Preciosidades sobre preciosidades: relatórios de novas descobertas, moléculas maravilhosas, infaziveis ontem - feitas hoje, reprodutivelmente, com facilidade. 0 químico lê acerca das incriveis propriedades dos novos supercondutores de alta temperatura, ferromagnetos orgânicos, solventes supercríticos. Novas técnicas de medida, rapidamente equipadas com acrónimos - EXAFS, INEPT, COCONOESY - permitem-Ihe decifrar mais expeditamente a estrutura daquilo que fez. A informação simplesmente flui. Não interessa se é em alemão, se é em inglês. É Química comunicada, excitante, viva.

Tomemos, contudo, outra perspectiva. Um humanista, observador inteligente e perceptivo, que dominou Shakespeare, Puchkine, Joyce e Paul Celan, vira-se para as páginas da mesma revista. Estou a pensar numa pessoa que está interessada no que se escreve e também em como e porque se escreve. 0 meu observador repara que a revista tem artigos pequenos, de uma a dez páginas de tamanho. Repara na abundância de referências, escolhos familiares para os eruditos literários, mas talvez com maior densidade (número de referências por linha de texto) do que nos textos eruditos das letras. Vê uma grande proporção da página impressa dedicada aos desenhos. Muitas vezes estes parecem ser imagens de moléculas, no entanto são curiosamente icónicos, faltando as designações completas dos átomos. As representações do químico não são projecções isométricas, nem desenhos com perspectiva real, e, contudo, são parcialmente tridimensionais. 0 meu observador lê o texto, curioso, talvez ignorando o calão, talvez penetrando nele com a ajuda dum amigo químico. Observa uma forma ritual. As primeiras frases começam muitas vezes: "A estrutura ligação e espectroscopia de moléculas do tipo $\mathrm{X}$ têm sido objecto de imenso interesse. ${ }^{a-z "}$ Há um uso generalizado da terceira pessoa e da passiva. Encontra poucas motivações pessoais expressas abertamente e poucas descrições do desenvolvimento histórico. Aqui e ali, no meio da linguagem neutra, vislumbra pretensões declaradas de realizações "um novo metabolito", "a primeira síntese", "uma estratégia geral", "cálculos independentes de parâmetros". Ao estudar muitos artigos, acha uma desoladora semelhança entre eles. No entanto, como é fácil de observar em certos artigos, também encontra estilo - uma maneira distinta de olhar 0 universo químico, ligando ciência, escrita e grafismo.

Eu quero olhar, agora sem me esconder atrás deste obserador, para a linguagem da minha ciência, tal como é expressa no veículo escrito essencial, 0 artigo na revista de Química. Vou argumentar que há muito mais num artigo do que transparece à primeira vista; que 0 que há é uma espécie de luta dialéctica entre 0 que 0 químico acha que deve ser dito (o paradigma, a norma) e aquilo que ele ou ela deve dizer para convencer os outros dos seus argumentos e realizações. Esta luta confere uma enorme dose de tensão suprimida ao artigo de aspecto mais inocente. Revelar essa tensão, afirmo eu, não é de modo nenhum um acto de fraqueza ou irracionalidade, mas sim o reconhecimento do humanismo profundo do acto criativo em ciência.

\section{O ARTIGO CIENTÍFICO: UMA BREVE HISTÓRIA}

Já havia Química antes das revistas de Química. Vinha descrita em livros, em panfletos, em cartas para os secretários das sociedades científicas. Estas sociedades, como, por exemplo, a Royal Society de Londres, fundada em 1662 , tiveram um papel crítico na disseminaçăo do conhecimento científico. As suas publicações periódicas ajudaram a desenvolver a combinação especial de medidas cuidadosas e formulação matemática que conferiram forma à nova $\mathrm{e}$ próspera ciência do tempo[2].

Os artigos científicos desse tempo são uma mistura curiosa de observação pessoal e discussão, com motivação, método, e muitas vezes história na primeira pessoa. Shapin,[3a] Dear [3b] $e$ Holmes[3c] deram argumentos convincentes para o início da codificação do estilo do artigo científico em França $e$ Inglaterra, no Século XVII. Acho que a forma do artigo de Química se tornou rígida por volta de 1830 ou 1840 e que isso aconteceu na Alemanha. A luta decisiva foi entre os fundadores da moderna Química alemã - pessoas como Justus von Liebig - e os Naturphilosophen. Neste período em especial, o último grupo teria sido representado pela escola de Goethe, mas manifestava-se noutros pontos da Europa, mesmo mais cedo, no Século XVIII. Os Filósofos Naturais tinham noções bem formadas, teorias globais, de como a Natureza se devia comportar, mas não se dignavam sujar as mãos para descobrir como a Natureza na verdade funcionava. Ou tentavam encaixar a Natureza no seu modelo filosófico ou poético, não se importando com o que diziam os nossos sentidos ou os seus prolongamentos, os instrumentos. 0 artigo científico evoluíu no Século XIX de modo a opôr-se à influência perniciosa dos Filósofos Naturais. A descrição ideal duma investigação científica deveria ocupar-se dos factos (muitas vezes designados implicita ou explicitamente como a verdade; voltaremos a isto mais à frente). Seria preciso acreditar nos factos, independentemente da identidade da pessoa que os apresentasse. Resultou disso que deveriam ser apresentados sem qualquer emoção (portanto na terceira pessoa) e sem julgamentos prévios de estrutura ou casualidade (dai a voz passiva, sem agente).

Os frutos deste modelo tipo reportagem foram imensos. A ênfase nos factos experimentais evidenciava o reprodutível. A concisão da língua alemã parecia a ideal para o paradigma em desenvolvimento. Criaram-se químicos especializados. 0 desenvolvimento da indústria química de corantes, que teve lugar posteriormente em Inglaterra e na Alemanha, é uma manifestação particularmente bem estudada da organização da nova química.

0 artigo de Química adquiriu neste período uma forma canónica ou ritual. Na Figura 1, reproduzo parte dum artigo típico desse período $[4,5]$. Reparem que já aparece a maior parte das características do artigo moderno - referências, parte experimental, discussão, diagramas. Só falta 0 agradecimento à Deutsche Forschungsgemeinschaft ou à National Science Foundation. 


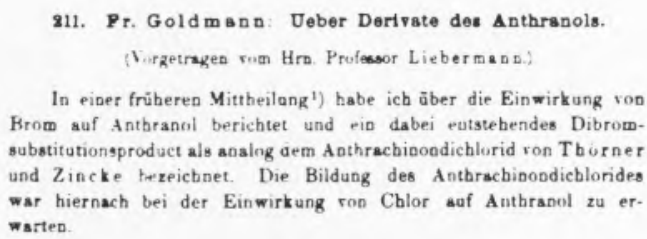

In einer früheren Mittheilang ${ }^{1}$ ) habe ich āber die Einwirkung von Brom suf Antbranoil berichtet und ein dabei eutstebendes Dibrom substitutionsproduct als analng aem Anthracbioondichlorid ron Thorner und $Z$ incke trezeictnet. Die Bildung des Antbrachinondicblorides war hiernach bei der Einwirkung ron Cblor auf Autbranol zu erwarted

Antbracbioondichlorid, Dicblorantbroa, $\mathrm{C}_{8} \mathrm{H}_{4} \underset{\mathrm{CCl}_{2}}{\mathrm{CO}} \mathrm{C}_{8} \mathrm{H}_{4}$

In eipe kalte concentrirte Lösung ron Antbranol in Cbloroform wurde während etwa 20 Minuten trockenes Cblorgas geleitet, wobe die Lõaung auf Zimmertemperatur erhalten warde. Nacb beendeter Reaction, bei der reichliche Chlorwasserstoffentwickluog stattiand,

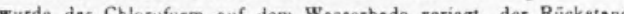

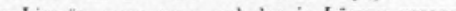
政 duct aus einer beissen Mischung von Benzol and Ligroỉn umkrystallisirt.

Die Substanz wird so in Form ron wasserklaren dünnen Prismen erhalten. Diequlben schmelzen bei $132-134^{\circ}$.

Die Vertindung ist in Benzol, Schwefelkoblenstuff. Chloroform sebr leicht, in kaltem Ligmin odier Aether ziemlich schwer löslich. Aus der Schwefelikoblenstufflioung orbält man die Substanz beim Verdunsten is schöben wasserklaren Krystallen.

\begin{tabular}{|c|c|c|c|}
\hline & \multicolumn{2}{|c|}{ Cisfunilon } & Ber. für $\mathrm{C}_{4} \mathrm{H}_{8} \mathrm{OCC}$ \\
\hline c & $5+6,2$ & - & $64.12 \mathrm{pCt}$. \\
\hline H & 3.2 .3 & - & 3.05, \\
\hline $\mathrm{CI}$ & - & $2 t, 96$ & 26.72, \\
\hline
\end{tabular}

Durch Kochen mit Eisessig ider Alkohol wird die Verbindung solletändig in Anthrachinon übergeführ. Die Cbloratome müseen daher in der Mittrlknhlenatoffrappe sich befinden. Die Virhindeng

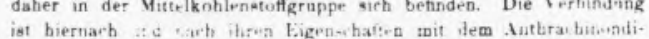

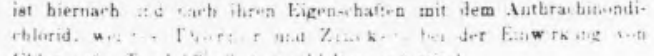

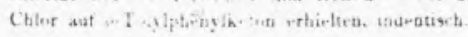

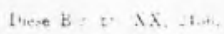

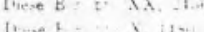

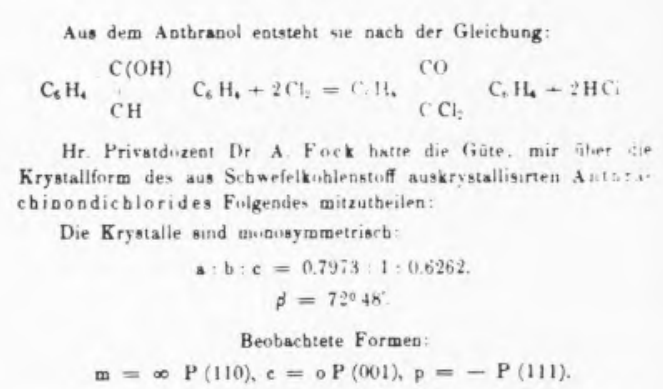

Die Krystalle bildea schwach gelblich gefärbte dũnne Pritmrn. die Basis tritt nur an einzelnen Individuen und 2 war ganz untefze ordnet auf

$$
\begin{array}{lc}
\text { Beib. } & \text { Herectinet } \\
m: m=110: 110=74^{\circ} 36^{\circ} & - \\
m: c=110: 001=76^{\circ} 24^{\circ} & - \\
p: c=111: 011=37^{\circ} 54^{\circ} & - \\
p: p=111: 111=45^{\circ} 30^{\circ} & 45^{\circ} 2^{\prime} \\
p: m=111: 110=3 \times 038^{\circ} & 3 \times^{\circ} 30 \\
p: m=111: 110=- & 71^{\circ} 25
\end{array}
$$

Spaltbarkeit nicht benbachtet.

Auch das analoge Anthrachinondibromid hat $\mathrm{Hr}$. Dr. For k za messen die Gũte gehabt, wobei er folgende Resultate erhiels:

Die Krystalle sind monosymmetriscb $\mathrm{a}: \mathrm{b}: \mathrm{c}=1.5009: 1: 1.4708$. $\beta=70^{\circ}+s^{\prime}$. Beobacblete Formen:

$=$ o $\mathrm{P}(001), \mathrm{p}=-\mathrm{P}(111), 0=+\mathrm{P}($ i11 $)$,

$y=1, P,(012), w=+2 P 2(121)$.

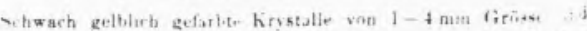

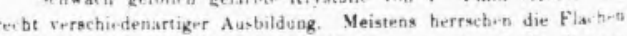
der inderen Pyratmide $p$ and der Basis ror. wabretid die Vitri:

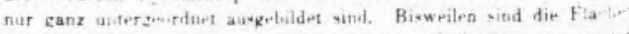

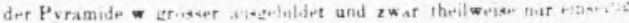

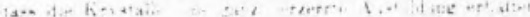

Figura 1. As duas primeiras páginas dum artigo típico de 1888 [4].

Na Figura 2, um artigo contemporâneo, aproximamo-nos do presente. Esta contribuição em especial, bastante importante, de O. J. Scherer e T. Brück [6], descreve um sistema tipo ferroceno em que um anel ciclopentadienilo foi substituído por $\mathrm{P}_{5} .0$ trabalho é original e significativo, mas eu quero concentrar-me mais no modo de apresentação do que no conteúdo. Em que é que este artigo difere do outro publicado há um século? A língua dominante mudou para inglês por razões geopolíticas[7]. Contudo, não me parece que haja muita mudança na construção $\mathrm{e}$ no tom do artigo. Claro que se comunicam coisas novas, maravilhosas. Medidas que levaram uma vida a fazer, demoram agora um milisegundo. Moléculas inimagináveis há um século são feitas facilmente e revelam a sua identidade, num relance, a conhecedores como nós. E é tudo comunicado numa revista mais espampa- nante, impressa com certeza em papel de pior qualidade, com melhores desenhos e impressão via computador, mas essencialmente na mesma forma. É melhor, é pior?

Bom, eu acho que é ambas as coisas. 0 sistema de transmissão de conhecimento através do artigo em revistas periódicas funcionou espantosamente bem durante dois séculos ou mais. Mas acho que há perigos reais (a que voltarei) implícitos nesta forma canónica actual. A minha principal preocupação é 0 que se passa ao escrever e ler um artigo científico, que é muito mais do que uma simples comunicação de factos. Para preparar a discussão do artigo científico, tenho que começar por dizer algo sobre 0 que eu penso que é a Ciência e a Química em particular.

\section{UMA VISÃO PESSOAL DA QUÍMICA}

Só a minha e de mais ninguém, e os outros hão-de vê-la de modo diferente[8]:

\section{A Ciência é a aquisição de conhecimentos sobre o mundo.}

Este sentido é claro na etimologia da palavra inglesa ou no alemão Wissenschaft ou Naturwissenschaft. Reparem que "verdade" não entra explicitamente nessa etimologia. Obviamente, a reprodutibilidade, a verificabilidade, a confiança, que são essenciais no esforço científico, dependem de medidas honestas. Os cientistas gostariam de pensar que adquirem a verdade (de valor ético e moral) e não apenas o conhecimento (completamente neutro; relembre-se a árvore do conhecimento do bem e do mal no Génesis). Mas gostava de chamar a atenção dos meus colegas para o perigo de fornecer ao mundo em geral uma imagem dos cientistas como seres que procuram a verdade, em vez do conhecimento de confiança[9]. Isso faz de nós padres, com as consequências inerentes. Suspeito que muito do interesse público nos casos raros de fraude em ciência tem a ver com o interesse malicioso do mundo em geral pelas falhas morais de 
$\left|\left(\eta^{5}-P_{5}\right) F e\left(\eta^{5}-C_{5} M_{5}\right)\right|$, a Pentaphosphaferrocene Derivative ${ }^{* *}$

By Otto J. Scherer* and Thomas Brück

After having demonstrated that cyclo- $\mathrm{P}_{5}$ could be stabilized as bridging ligand in the mixed-valence triple-decker complex $1,{ }^{[17]}$ we then attempted to realize the classical

$$
\left[\left(\eta^{5}-\mathrm{C}_{5} \mathrm{Me}_{5}\right) \operatorname{Cr}\left(\mu, \eta^{5}-\mathrm{P}_{5}\right) \operatorname{Cr}\left(\eta^{5}-\mathrm{C}_{5} \mathrm{Me}_{5}\right)\right]
$$$$
1
$$

sandwich coordination of this ligand (cyclo- $\mathrm{P}_{5}^{\oplus}$ as $6 \pi$ electron donor). Success was achieved upon cothermolysis of $\mathbf{2}$ with white phosphorus.

Pentamethylpentaphosphaferrocene 3 forms, sublimable, green crystals which can be handled in the presence of air and which begin to melt (with partial sublimation and slight decomposition) at $270^{\circ} \mathrm{C}$ when heated in a sealed tube. $\mathbf{3}$ is very soluble in dichloromethane, readily soluble in benzene and toluene, and moderately soluble in pentane.

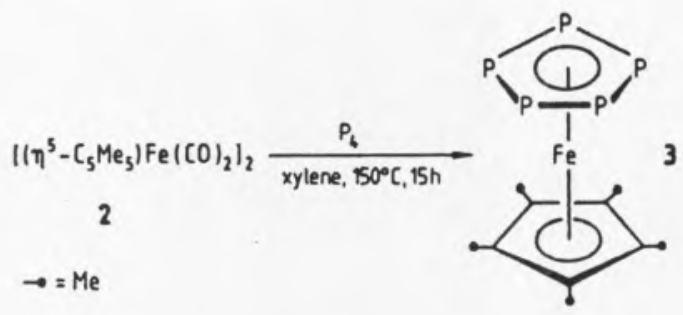

In the 'H-NMR spectrum $\left(200 \mathrm{MHz}, 293 \mathrm{~K}, \mathrm{C}_{6} \mathrm{D}_{6}\right.$, TMS int.) of 3 a sharp singlet is observed at $\delta=1.08$ which is shifted $0.6 \mathrm{ppm}$ upfield compared to that of decamethylferrocene $\left[\left(\eta^{5}-\mathrm{C}_{5} \mathrm{Me}_{5}\right)_{2} \mathrm{Fe}\right]{ }^{4} .^{|3|}$ In comparison to the ${ }^{13} \mathrm{C}|\mathrm{H}| \mathrm{H}$-NMR signals of $4^{[2,3 \mid}$ those of $3^{|2|}$ are shifted slightly downfield. The ${ }^{31} \mathrm{P} \mid$ 'H $\mathrm{H}$-NMR signal shows a continuous downfield shift within the series triple-decker 1 $\left(\delta=-290.5^{(11)}\right)$, monophosphaferrocene $\left[\left(\eta^{5}-\mathrm{C}_{5} \mathrm{H}_{5}\right) \mathrm{Fe}\left(\eta^{5}\right.\right.$ $\left.\left.\mathrm{PC}_{4} \mathrm{H}_{4}\right)\right] 5\left(\delta=-67.5^{(4)}\right), 3\left(81.01 \mathrm{MHz}, \mathrm{C}_{6} \mathrm{D}_{6}, 85 \% \mathrm{H}_{3} \mathrm{PO}_{4}\right.$ ext., $\delta=153.0(\mathrm{~s}))$, and $\operatorname{Li}\left(\mathrm{P}_{5}\right)\left(\delta=470^{(5)}\right)$. In the mass spec-

[•I Prof. Dr. O. J. Scherer, Dipl.-Chem. T. Brück

Fachbereich Chemie der Universităt

Erwin-Schrödinger-Strasse, D-6750 Kaiserslautern (FRG)

[*.] This work was supported by the Fonds der Chemischen Industrie. trum, ${ }^{121}$ the most intense peak is the molecular peak of 3 . followed by the peak for $M^{\ominus}-P_{2}$. So far, all attempts to prepare a single crystal suitable enough for an $\mathrm{X}$-ray structure analysis have failed, both by sublimation as well as recrystallization. cyclo- $\mathrm{P}_{5}^{\ominus}$ is probably formed from $\mathrm{P}_{3}^{\ominus}$ and $\mathrm{P}_{2}{ }^{|6|}$

\section{Experimental}

A mixture of 2 [7] $(980 \mathrm{mg}, 2.3 \mathrm{mmol})$ and $\mathrm{P}_{4}(1500 \mathrm{mg}, 12.1 \mathrm{mmol})$ in xylene $(80 \mathrm{~mL})$ was stirred under reflux for $15 \mathrm{~h}$ and the insoluble material removed by filtration on a D3 frit and extracted three times with $80 \mathrm{~mL}$ each of $\mathrm{CH}_{2} \mathrm{Cl}_{2}$ (393 mg of residue after drying under high vacuum). The solvent was removed from the combined extracts under oil-pump vacuum. After three extractions with $50 \mathrm{~mL}$ each of pentane there remained $726 \mathrm{mg}$ of a brown solid whose composition could not be unequivocally established. After removal of the solvent from the green extracts (oil-pump vacuum), the residue remaining behind was sublimed. At $60^{\circ} \mathrm{C} / 0.01$ torr, excess phosphorus was removed between $90^{\circ}$ and $110^{\circ} \mathrm{C}$, green needles sublimed on the wall of the (175 me wall of the glass vessel. Recrystallization from pentane furnished $175 \mathrm{mg}$ of $\mathbf{3}$ (yield
$11 \%$ ). Correct elemental analysis.

Received: October 20, 1986 supplemented: November 7, 1986 [Z 1957 IE] German version: Angew. Chem. 99 (1987) 59

[1] O. J. Scherer, J. Schwalb, G. Wolmershăuser, W. Kaim, R. Gross, Angew: Chem. 98 (1986) 349; Angew. Chem. Int. Ed. Engl. 25 (1986) 363.

[2] ${ }^{3} \mathrm{C}$ ' 'HF-NMR ( $50.28 \mathrm{MHz}, \mathrm{C}_{0} \mathrm{D}_{6}$. TMS intern) $3: \delta-90.6\left(\mathrm{~s}: \mathrm{C}_{3} \mathrm{Me}_{3}\right)$, $10.6\left(\mathrm{~s} ; \mathrm{CH}_{3}\right) ; 4: \delta=78.5\left(\mathrm{~s} ; \mathrm{C}_{3} \mathrm{Me}\right.$ ) $), 9.8\left(\mathrm{~s} ; \mathrm{CH}_{3}\right)$. El-MS $(70 \mathrm{eV})$ of 3 : $m / z 346\left(M^{\circ}, I_{\text {ret }}=100 \%\right), 284\left(M^{\circ}-P_{2}, 91 \%\right), P_{4}(19.8 \%), P_{3}(7.9 \%), P_{2}$ $(53 \%), P(7.8 \%)$ and further, weak intensity lines.

[3] Cf. : J. L. Robbins, N. Edelstein, B. Spencer, J. C. Smart, J. Am. Chem. Soc. 104 (1982) 1882.

[4] F. Mathey, Sinuct. Bonding (Berlin) 55 (1983) 153.

[5] M. Baudler, Phosphorus Sulfur, in press: M. Baudler, D. Düster, D. Ouzounis, Z. Anorg. Allg. Chem., in press.

[6] Cf. also the theoretical studies on $N_{i}$ and its complex stabilization. M. T Nguyen, M. Sana, G. Leroy, J. Elguéro, Can. J. Chem. 61 (1983) 1435: M. T. Nguyen, M. A. McGinn, A. F. Hegarty, J. Elguéro, Polyhedron 4 (1985) 1721.

[7] D. Catheline, D. Astruc, Organometallics 3 (1984) 1094, and references cited therein. parte dos artistas põe a enfâse na da criação. Bem, eu acho que muito do que fazemos em ciência é criação, especialmente em Química. A sintese de moléculas ainda não existentes na Terra é uma prova clara disto. A síntese é uma maravilhosa acumulação de descoberta e criação que aproxima a Química das artes e da engenharia[10].

\section{A Ciência é em parte descoberta, em parte criação}

Uso o termo descoberta no sentido de revelar algumas leis da natureza, talvez obscurecidas, e o termo criação no sentido de fazer coisas novas. Quando descrevem o seu trabalho, os cientistas, na sua maior parte, realçam a metáfora da descoberta, ao passo que a maior

\section{A Ciência é feita por seres humanos e pelos seus instrumentos}

Isto quer dizer que é feita por seres humanos faliveis. Claro que as forças que nos levam a adquirir conhecimento são a curiosidade e 0 altruis- mo, motivos racionais. Mas 0 acto de criar tem igualmente raízes no irracional, nas águas sujas e escuras da mente, onde medos, poder, sexo, traumas infantis nadam com todos os seus movimentos misteriosos e escondidos. $E$ instigam-nos. Na sequência do Mozart e Salieri de Puchkine, ou da sua reencarnação moderna na peça Amadeus de Peter Schaffer e no filme nela baseado: a música angelical (leiase Química) pode ser trazida para este mundo por veículos muitos grosseiros. Não só 0 carácter e as motivações íntimas não interessam, como 0 lado "sórdido" até pode ser a força motivadora do acto criativo. 


\section{A Ciência avança de certo modo segundo regras}

0 modelo moderno do pensamento científico, associado neste século talvez ao nome de Karl Popper, começa com observações mensuráveis, reprodutíveis. Depois, formulam-se hipóteses ou modelos alternativos para explicar estas observações. Finalmente, com a ajuda de mais experiências ou de uma teoria de confiança, as hipótese são examinadas, eliminadas uma a uma, até ficar apenas a que tem mais probabilidade de ser a certa. Às vezes funciona assim[11], embora seja curioso que aconteça principalmente com a ciência do dia a dia e não com a ciência que desbrava novos caminhos. Mas será que este modelo se aplica à sintese moderna duma molécula não natural, como, por exemplo, o dodecaedrano, uma espantosa molécula $\mathrm{C}_{2} \mathrm{H}_{20}$ com a forma que 0 nome sugere? Ou o desenvolvimento da técnica de ressonância magnética nuclear, tão útil para um químico à procura do arranjo espacial dos átomos como para um médico à procura dum tumor no cérebro?

\section{A Ciência depende da argumentação}

"Argumentação" tem vários significados - pode ser tomado simplesmente como um modo de raciocínio, a constatação dum facto; a palavra pode também significar desacordo, a confrontação dos opostos. Eu diria que os dois sentidos são essenciais em ciência: raciocínio lógico e desapaixonado $e$ convicção apaixonada de que um (modelo, teoria, medida) tem razão e outro não tem. Acho que a criatividade cientifica tem raizes na tensão interna, dentro de uma e mesma pessoa, de saber que tem razão e que essa convicção tem que ser provada a contento dos outros. Num artigo de revista.

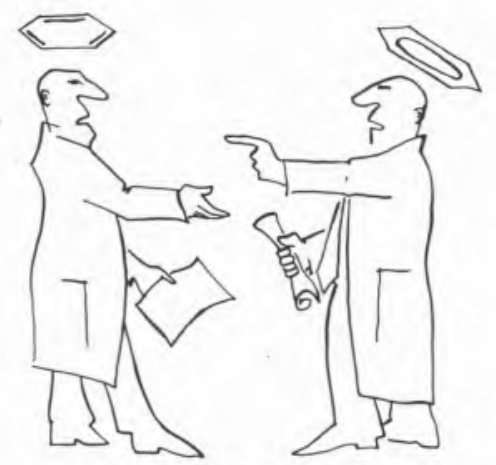

\section{Como sistema, a Ciência funciona}

Os cientistas lutam individualmente para adquirir conhecimento e são motivados na sua luta por muitas e complexas razões. Como os investigadores são humanos, estão sujeitos não só à imprecisão, mas também, por vezes, a preconceitos. Espantosamente, o erro e os preconceitos do químico como individuo não interessam para o progresso da Química. A Química como ciência, a actividade colectiva de meio milhão de pessoas do mundo, que são químicos, avança apesar dos erros de cada um deles. [12]. A Ciência tem imensos processos de auto-correcção: o mais importante é que, quanto mais interessante for a observação ou teoria, maior é a probabilidade de outros a repetirem para verificar. Às vezes fazem-no por razões "erradas" - na convicção de que a observação inicial devia estar errada. Não importa porque é que um químico invididual repete uma sintese crítica, ou experimenta uma teoria alternativa. A Quimia avança.

E, contudo, é importante que um químico tente provar que 0 mecanismo proposto por outro está errado, ou tente sintetizar uma molécula em primeiro lugar, porque sem o impulso humano nada seria realizado. Esta nossa ciência é uma curiosa criação - um sistema útil de conhecimento, excitante, incrivelmente resistente, construído por pessoas imperfeitas e que depende destas imperfeições para progredir.

\section{A Química é a ciência das moléculas}

É preciso dizer mais? Há limites na definição, mas as moléculas, nas diatómicas, à anidrase carbónica e ao $\mathrm{YBa}_{2} \mathrm{Cu}_{3} \mathrm{O}_{7-x}$ são 0 nosso negócio. $\mathrm{E}$ são um grande negócio - fazem-se por ano $10^{11}$ quilos de ácido sulfúrico e mais quilos de amónia do que o número de seres humanos.

\section{A Química não é redutível à Física}

0 reducionismo é algo com que nos têm acorrentado há dois séculos. Quero indicar com este termo o estabelecimento de uma hierarquia de ciências: Ciências Sociais, Biologia, Química, Física, e, por corolário, uma definição de conhecimento numa ciência como sendo a redução ao nivel seguinte, mais profundo[13]. Sinto que os cientistas aceitam isto como ideologia, mas não repre- senta a realidade do trabalho produtivo em nenhuma ciência e a ideia é perigosa. Hei-de voltar aos perigos mais tarde. 0 que acho que acontece, na realidade, é que há um conjunto de objectos, questōes e conceitos que evolui de cada actividade dos seres humanos. Podemos-lhes chamar categorias. 0 conhecimento pode ser definido verticalmente, numa maneira reducionista, mas também horizontalmente, em termos das questões $e$ dos conceitos dessa ciência. A maior parte dos conceitos úteis da Química (para 0 químico: aromaticidade, o conceito de grupo funcional, efeitos esteroquímicos, tensão num anel) é imprecisa. Quando se reduzem à Física, tendem a desaparecer[14]. Mas à custa deles foi e é desenvolvida uma Química maravilhosa.

\section{O QUE ACONTECE REALMENTE NUM ARTIGO QUÍMICO}

Podia prosseguir e fazer uma lista de outros pontos de vista sobre Ciência e Química, mas para mim estes são suficientes para começar uma discussão sobre 0 artigo químico e 0 que dele transparece.

Na sua aparência, o artigo pressupõe ser uma comunicação de factos, talvez uma discussāo, sempre desapaixonada e racional, de mecanismos alternativos e teorias, e uma escolha, mais ou menos convincente, entre eles. Ou a demonstração de uma nova técnica de medida, ou uma nova teoria. E, notavelmente, 0 artigo funciona. Uma parte experimental detalhada na Angewandte Chemie em alemão ou inglês pode ser reproduzida (de facto, a facilidade com que pode ser reproduzida é outra história [15]) por alguém com um conhecimento rudimentar de qualquer das línguas, trabalho em Okasaki ou Krasnoyarsk. Esta característica subjacente de reprodutibilidade potencial ou real é para mim a melhor prova de que a ciência é um conhecimento de confiança[16].

Mas num artigo científico há muito mais do que aquilo que os olhos vêem. Encontro isso nos temas seguintes, muitos dos quais são também descritos $e$ analisados dum modo muito mais profundo num livro notável de David Locke, Science as Writing[17].

Arte

0 artigo de química é uma criação artística. Deixem-se explicar o que pode 
ser entendido como um exagero radical. 0 que é a Arte? Uma coisa para cada pessoa. Um aspecto da arte é a estética, outro o provocar uma resposta emocional. Noutra tentativa de construir uma definição ilusória dessa actividade humana que engrandece a vida, direi que a arte é a procura da essência de algum aspecto da natureza ou duma emoção por um ser humano. A arte é uma construção humana e obviamente não natural.

0 que se escreve numa revista cientifica não é uma representação verdadeira e fiel (admitindo que tal fosse possivel) do que acontece. Não é um caderno de laboratório e sabe-se bem que esse caderno, por sua vez, só é um guia parcial do que realmente se passou. É um texto construído, com mais ou menos (espera-se que mais) cuidado, por um homem ou uma mulher. Muitos dos obstáculos que se opuseram à síntese ou à construção do espectrómetro foram expurgados do texto. Os que restam servem 0 objectivo retórico (que não é mais traco só porque é suprimido) de nos fazer pensar melhor do autor. Os obstáculos que são transpostos põem em relevo a história do sucesso.

0 artigo de Química é uma construção abstracta duma actividade quimi$\mathrm{Ca}$, feita pelo homem. Se se tiver sorte, provoca uma emoção estética ou emocional nos seus leitores.

Há alguma razão para ter vergonha em admitir que as nossas comunicações não são espelhos perfeitos, mas sim, numa parte substancial, textos literários? Acho que não. De facto, acho que há algo requintadamente belo nos nossos textos. Estas "messages that abadon", parafraseando Jacques Derrida[18], na realidade deixam-nos, voam para leitores atentos em todos os paises do mundo. São lidos, na sua língua original, e compreendidos; proporcionam prazer $e$, ao mesmo tempo, podem ser transformados em reacções químicas, em coisas novas e reais. Seria inacreditável, se não soubéssemos que acontece milhares de vezes por dia.

\section{História}

Uma das características mais citadas para distinguir a ciência das artes é o uso mais óbvio de cronologia na ciência, explicitada no uso abundante de referências. Mas é história verdadeira ou uma versão abonecada?

Um guia de estilo químico muito em voga no meu tempo admoestava: "... uma coisa a evitar é a narração exaustiva da cronologia do trabalho num problema. A história completa duma investigação pode incluir uma hipótese inicial errada, um indício falso, uma interpretação errada de direcções, uma circunstância fortuita; tais detalhes terão possivelmente valor como divertimento numa conferência sobre investigação, mas estão certamente deslocados num artigo formal. Um artigo deve apresentar, 0 mais directamente possivel, o objectivo do trabalho, os resultados e as conclusões; os acontecimentos de acaso ao longo do percurso têm pouco interesse para o relatório definitivo[19]."

Sou a favor da concisão, da economia de frase. Mas os conselhos deste guia de estilo, quando seguidos, levam a autênticos crimes contra a humanidade do cientista. Para apresentar uma versão asséptica, paradigmática dum estudo químico, suprimem-se muitos dos actos realmente criativos. Entre estes estão as "circunstâncias fortuitas" - todos os elementos de "serendipity", da intuição criativa em acção[20].

Tomada de outra forma, a receita descrita acima para um bom estilo científico demontra muito claramente que 0 artigo químico não é uma verdadeira representação do que transpirou ou foi aprendido, mas sim um texto construído.

\section{Linguagem}

Os cientistas acham que 0 que dizem não é influenciado pela língua em que 0 dizem, referindo-se não só à língua em si (alemão, francês, chinês), mas também às palavras dentro dessa língua. Acham que as palavras utilizadas, desde que bem definidas, são representações correctas duma realidade material subjacente que eles, os cientistas, descobriram ou matematizaram. Se as palavras são representações fiéis dessa realidade, elas devem ser traduziveis sem ambiguidades para qualquer língua.

Esta posição é defensável - logo que a sintese do novo supercondutor de alta temperatura $\mathrm{YBa}_{2} \mathrm{Cu}_{3} \mathrm{O}_{7-x}$ foi descrita, foi reproduzida em cem laboratórios à volta do globo.

Mas a situação real é mais comple$x a$. Vendo de outra maneira, as palavras são tudo 0 que temos. $E$ as palavras que temos, em qualquer língua, são mal definidas, ambiguas. Um dicionário é um ciclo vicioso - experimentem e vejam como uma cadeia de definiçôes se fecha rapidamente sobre si própria. Raciocínio e debate, tão essenciais para a comuni- cação em ciência, avançam com palavras. Quanto mais controverso 0 argumento, mais simples e mais carregadas as palavras [21].

Como há-de um químico sair vivo disto? Talvez vendo o que alguns dos nossos colegas de linguística e crítica literária aprenderam durante 0 último século[22]. A palavra é um sinal, uma peça dum código. Significa qualquer coisa, claro, mas esse significado tem que ser descodificado ou interpretado pelo leitor. Se dois leitores tiverem dois mecanismos de descodificação diferentes, eles têm diferentes leituras e diferentes significados. A razão pela qual a química funciona em todo o mundo, permitindo à BASF construir uma fábrica na Alemanha ou no Brasil e esperar que funcione, é que os químicos aprenderam o mesmo conjunto de símbolos na sua educação.

Acho que isto explica, em parte, o que Carl Friedrich von Weizsäcker verificou num sugestivo artigo sobre "A Linguagem da Física"[23]: Se se examinar em detalhe uma conferência sobre investigação em Física (leia-se Química), vê-se que ela está cheia de frases imprecisas, incompletas, paragens, etc. 0 seminário é em geral feito extemporaneamente, sem notas, ao passo que os humanistas na maior parte das vezes lêem um texto palavra por palavra. A linguagem das conferências de Química ou de Física é muitas vezes imprecisa. No entanto, os químicos compreendem estas apresentações (pelo menos alguns...). A razão é que a conferência de Química invoca um código, um conjunto do conhecimento comum que eles partilham. Nâo é preciso acabar a frase - já toda a gente percebeu de que se tratava a meio dela.

\section{Grafismo}

A semiótica da Química é mais aparente na estrutura das moléculas que adornam quase todas as páginas de uma revista de Química, que identificam num relance um artigo como sendo de Química[24, 25]. 0 dado, apenas velho de um século, é que a estrutura das moléculas interessa. Não é só saber quais são os constituintes atómicos. É também como os componentes atómicos se ligam, como estão arranjados no espaço tridimensional e quão facilmente se afastam da sua posição de equilíbrio. A estrutura duma molécula, pela qual eu refiro a disposição no espaço de núcleos e electrões, tanto a estrutura estática no 
equilíbrio como a sua dinâmica, determina todas as propriedades físicas, químicas e, em última análise, biológicas da molécula. É essencial para os químicos comunicarem uns aos outros a informação estrutural tridimensional. Os meios para essa comunicação são bidimensionais - uma folha de papel, um écran. Surge, portanto, imediatamente, um problema de representação.

Na verdade, o problema já lá está. 0 que é um modelo "ball-and-stick" de uma molécula? É a realidade? Claro que não. 0 modelo é apenas uma representação das posições de equilíbrio dos núcleos, mais alguns pressupostos sobre ligação. Há um interessante video do laboratório de F. P. Brooks, Jr., da Universidade de Carolina do Norte intitulado "Como é uma proteína?" Mostra 40 representações diferentes (fazendo-me lembrar uma colecção de gravuras em madeira de Hokusai chamada " 36 vistas do Monte Fuji") de uma e só uma enzima, superóxido dismutase - um modelo "ball-and-stick", um modelo "space-filling", o campo electrostático sentido por uma carga-sonda perto da molécula, e por ai a fora[26].

Deixem-me voltar ao problema de comunicação. Os químicos são compelidos a comunicar informação tridimensional em duas dimensões. Mas não têm talento para isso. Os jovens não são escolhidos nem se tornam químicos com base na sua habilidade artística.

Portanto as pessoas têm que fazer aquilo para que não têm jeito. É a vida! Os químicos sobrevivem, à custa de inventar um código para comunicar estruturas tridimensionais. $E$ treinam pessoas nesse código. Partes desse código são conhecidas dos químicos como projecções de Fischer ou Newman, ou como a representação traço-cunha. A molécula de etano, $\mathrm{C}_{2} \mathrm{H}_{6}$, é representada em duas geometrias possiveis, $\mathbf{1}$ e $\mathbf{2}$.

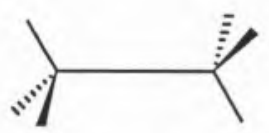

alternado

1

Figura 3. Algumas das maneiras como a molécula de $\mathrm{C}_{2}$ aparece neste mundo. No sentido dos ponteiros do relógio, começando às $10 \mathrm{~h} 30 \mathrm{~m}$ : a) algumas curvas de energia potencial para a molécula de $\mathrm{C}_{2}$ diatómica [29a]; b) etano, etileno, acetileno; c) um com-
Reparem noutra peça do código: 0 carbono é o vértice do gráfico que tem quatro linhas ligadas a ele, mas não tem escrito C. Há hidrogénios no fim das linhas. Também não têm nomes. A notação é simples: uma linha sólida está no plano do papel, uma em forma de cunha para a frente, uma tracejada para trás. Isto pode ser 0 suficiente para algumas pessoas verem estas estruturas erguerse do papel, mas os circuitos neurónicos que controlam a representação ficam gravados para o resto da vida quando se mexe (com as mãos, não num computador) num modelo "ball-and-stick", olhando para o desenho.

É fascinante ver estruturas químicas flutuando nas páginas de qualquer revista e constatar como, a partir dessa informação mínima, as pessoas conseguem realmente ver as moléculas na sua imaginação. Os indícios da tridimensionalidade são mínimos. As moléculas flutuam e geralmente fica-se desencorajado quando se tenta pôr uns planos de referência para ajudar a vê-las (3 vs. 4).
As políticas das revistas, as suas limitações económicas e a tecnologia disponível limitam não só o que é impresso, mas também o que nós pensamos acerca das moléculas. Tome-se 0 norbornano, $\mathrm{C}_{7} \mathrm{H}_{12}$, molécula 3. Até cerca de 1950, nenhuma revista no mundo estava preparada para compôr esta estruturas como 3. Em vez disso, ela aparecia na revista como 6.

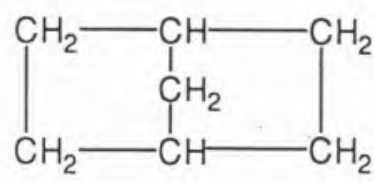

6

Ora toda a gente sabia, desde 1874 , que 0 carbono era tetraédrico, significando isto que as suas quatro ligações se formavam segundo as quatro direcções que radiam do centro dum tetraedro para os seus vértices. Podem ver esta geometria nos dois átomos de

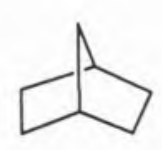

3

Alguns químicos confiam tanto no código que nem desenham $\mathbf{3}$, mas sim $\mathbf{5}$. Qual é a diferença? Uma linha "cruzada" em vez de "interrompida". Um indício tão trivial para reconstruir a tridimensionalidade, como o de uma parte da molécula estar atrás da outra, é dado em $\mathbf{3}$, falta em $\mathbf{5}$ ! A pessoa que desenha $\mathbf{5}$ está a fazer muitos pressupostos sobre a sua audiência. Eu aposto que ele ou ela nem pensa nisso.

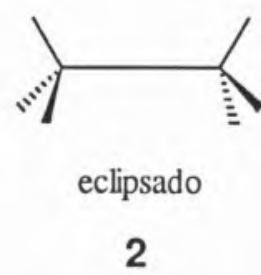

plexo dinuclear de tântalo com $\mathrm{C}_{2}$ [29b]; d) 0 agregado $\mathrm{Ru}_{4} \mathrm{C}_{2}$ [29c]; e) $\mathrm{C}_{2}$ dentro dum agregado de $\mathrm{CO}_{3} \mathrm{Ni}_{7}$ [29d]; f) carboneto de cálcio; g) DyCoC 2 [29e]; h) $\mathrm{Gd}_{12} \mathrm{C}_{6} \mathrm{I}_{17}$ [29f]. carbono das estruturas 2 e $\mathbf{3}$. Teria sido fácil adquirir ou construir modelos moleculares. No entanto, eu suspeito que a imagem ou ícone do norbornano que um químico típico tinha na cabeça por volta de 1925 era 6 e não 3. Estava condicionado pelo que via na revista ou livro de texto - uma imagem. Era levado a actuar, ao sintetizar uma molécula derivada desta, por exemplo, por aquela imagem irrealista.

Talvez não seja diferente da maneira como encaramos o romântico na nossa vida, equipados com um conjunto sortido de imagens soltas saídas de novelas e filmes.

\section{Estilo}

Todos os manuais de escrita científica que tenho visto exortam ao uso dum estilo impessoal, sem agente, super-racional. Por favor, meus senhores, dêem-nos os factos e só os factos!

Os meus artigos podem-se reconhecer numa revista só pela proporção 
de espaço dado ao material gráfico ou ao tracejado das minhas orbitais. Os artigos de $R$. B. Woodward eram reconheciveis pela elegância (construída) do seguimento da história científica e, na elegância correspondente, pela cadência das suas palavras. Sou capaz de ler um artigo de Jack Dunitz, de Rolf Huisgen, Rudolf Hoppe ou Bill Doering e ouvir as suas vozes nestes artigos, com tanta certeza como oiço a voz de $A$. $R$. Ammons, um grande poeta americano, ou de Bertold Brecht, um alemão, quando vejo o seu trabalho numa página impressa.

Ter um estilo está na natureza de qualquer ser humano criativo. Por que razão eu havia de escrever a minha teoria da mesma maneira que Bill Goddard, um teórico que admiro, quando ninguém espera que Karlheinz Sotckhausen e Pierre Boulez escrevam peças para piano com a mesma sonoridade?

\section{Lutas Dialécticas}

Um artigo científico agradável, equilibrado, pode esconder fortes correntes emocionais, manobras retóricas e jogos de poder. Uma já foi referida - 0 desejo de convencer, o grito "eu tenho razão, ninguém mais tem razão", confrontando-se com as regras estabelecidas de civismo que supostamente regem o comportamento académico. Depende do indivíduo o ponto onde este equilibrio é abalado.

Outro diálogo de que não se ouve falar é entre experiência e teoria. Não há nada de especial na relação amor-ódio entre experimentalistas e teóricos em Química. Podem substituir por "escritor" e "crítico" e falar de literatura ou encontrar 0 análogo na economia. As linhas mestras da relação são facilmente caricaturadas - os experimentalistas acham que os teóricos não são realistas, que constroem castelos no ar. No entanto, precisam das estruturas de conhecimento que os teóricos proporcionam. Os teóricos podem desconfiar das experiências, desejar que as pessoas fizessem aquela experiência que falta, mas onde estariam os teóricos se não houvesse
Uma manifestação engraçada dos sentimentos em relação a esta questão pode ser encontrada na discussão quase teórica, às vezes longa, dos artigos experimentais. Estas secções contêm, em parte, uma verdadeira busca de explicações, mas, por outro lado, o que se

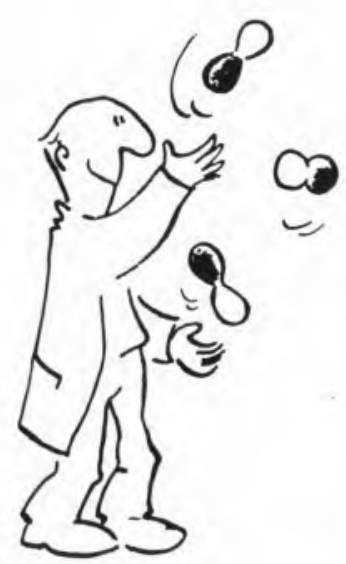

encontra nelas é uma tentativa para usar 0 ideal reducionista aceite (com a sua exagerada adoração do mais matemático) - para impressionar os colegas. Pelo contrário, nos meus artigos, geralmente ponho mais referências a trabalho experimental do que devia, porque estou a tentar "comprar tempo de credibilidade" da minha audiência experimentalista. Se eu mostrar aos químicos experimentais que conheço o seu trabalho, talvez eles me concedam algum tempo e oiçam as minhas especulações.

Outra luta, relacionada, é entre Química pura e aplicada. É interessante reflectir que esta separação tem talvez as suas raízes na Alemanha do meio do século XIX; parece a este observador que na outra potência da época, a Inglaterra, a distinção era menos rígida. É muito típico de um artigo de Química pura e procura duma justificação em termos de aplicações industriais. Mas ao mesmo tempo, há como que um recuo, uma falta de vontade de lidar com 0 mundo sem regras, tremendamente complicado de, por exemplo, a catálise industrial. E, nos meios industriais, há uma procura de credenciais académicas (muito típica, por exemplo, dos líderes da indústria química na Alemanha).

\section{Id liberta-se}

Uso a palavra sujeito no sentido psicanalítico, referindo-me ao complexo de desejos e terrores instintivos que habitam 0 inconsciente colectivo. Por um lado, estes impulsos irracionais, onde figuram proeminentemente 0 sexo e a agressão, são 0 nosso lado escuro. Por outro lado, eles providenciam a força motriz da actividade criadora [27].

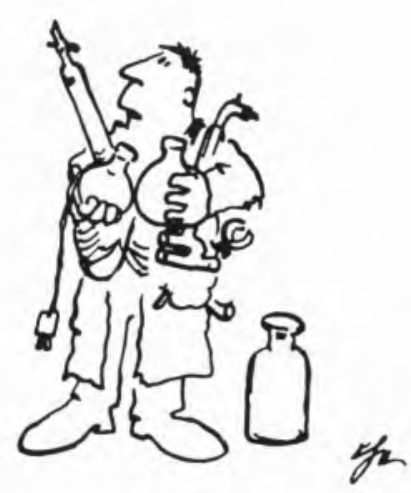

0 irracional parece ter sido efectivamente suprimido do mundo escrito da ciência. Mas, claro, os cientistas são humanos, não obtante pretenderem fortemente não o ser. As forças ilógicas internas empurram para fora. Para onde? Se não são autorizadas a aparecer à luz do dia, na página impressa, elas rastejam ou explodem de noite, às escondidas, onde ninguém vê como se é desagradável. Refiro-me, obviamente, ao processo de avaliação anónimo e e às incriveis respostas irracionais libertas por bons cientistas, geralmente racionais. É preciso desinibir de vez em quando..

Na verdade, acho que o que salva o artigo de Química da insipidez é que a sua linguagem está sob tensão. Estamos a tentar comunicar coisas que talvez não possam ser transmitidas em palavras mas exijam outros sinais - estruturas, equações, gráficos. E estamos a tentar, a todo 0 custo, eliminar a emoção daquilo que dizemos. 0 que é impossivel. Assim as palavras que dizemos sobrecarregamse, de vez em quando, com a tensão de tudo 0 que não foi dito...

Enfim, acontecem muitas coisas num artigo científico. Vou poupá-los aos quadros que tenho visto pendurados em muitos laboratórios, que apresentam 0 verdadeiro significado de frases feitas. Como "Um regime de arrefecimento lento ao longo de quatro semanas produziu $90 \%$ de rendimento de cristais pretos de..." quer dizer que "Fui de férias e esqueci-me de lavar o balão. Quando voltei..." E por ai fora.

Quero voltar à complexidade de decidir 0 que é verdadeiro no processo científico. Num artigo recente, Harald Weinrich [28] descreve 0 artigo clássico de Watson e Crick sobre a estrutura do 
DNA na Nature em 1953. É sucinto, tem uma sequência dedutiva, é elegante. David Locke, no seu livro, analisa a estrutura retórica e 0 uso da ironia no mesmo artigo[17]. Acho que a maior parte dos leitores fica imediatamente convencida de que 0 modelo de Watson e Crick era 0 verdadeiro e que tinha que ser assim. E é assim (com umas variações mínimas nos esquemas de ligações de hidrogénio em formas pouco vulgares de DNA). 0 modelo de Watson e Crick estava e está certo. Pouco mais é preciso.

Mas depois, em 1968, Watson escreveu um livro, "A Dupla Hélice", em que conta a história do que realmente aconteceu. Claro que é uma história egoista e pouco simpática ou imparcial para Rosalind Franklin e outros. A história de Watson faz lembrar uma das quatro versões do mesmo acontecimento contadas no genial filme Rashomon de Akira Kurosawa. São precisas as outras versões, que alguns historiadores nos proporcionaram. Mas não se pode questionar que a descrição de Watson é vibrante e cheia de vida. Conta-nos como viu a verdade e acho que é um grande livro.

Então (e aqui estou a seguir Weinrich) 0 que é a verdade: 0 artigo de
Watson e Crick de 1953 ou o livro de Watson de 1968? 0 último diminui o primeiro? Isto exige reflexão.

\section{Que fazer?}

Tentei desmontar 0 artigo científico, calcificado na sua presente forma há cem anos, roubando linguagem à teoria da crítica. Acho que teria feito isto melhor com um texto à minha frente, mas corria o risco de me porem um processo por difamação ou de perder amizades. $E$ faz parte da natureza humana não sermos capazes de criticar verdadeira e profundamente o nosso próprio trabalho. Portanto, não o posso fazer a mim próprio. Mas tenho a certeza de que todos os químicos conhecem soberbos exemplos daquilo a que me refiro, em especial no trabalho dos cientistas de que menos gostam.

Faço esta desmontagem com cuidade e sem malícia. Gosto muito desta ciência molecular. Gosto da sua riqueza e da sua simplicidade subjacente, mas, acima de tudo, da variedade que dá vida e riqueza e ideia de conjunto a toda a Química. Deixem-me dar um exemplo na Figura 3. Vejo $\mathrm{C}_{2}$ num arco de carbono $\mathrm{e}$ na cauda do cometa de Halley[29a]. Vejo-o no acetileno, no etileno, no etano.
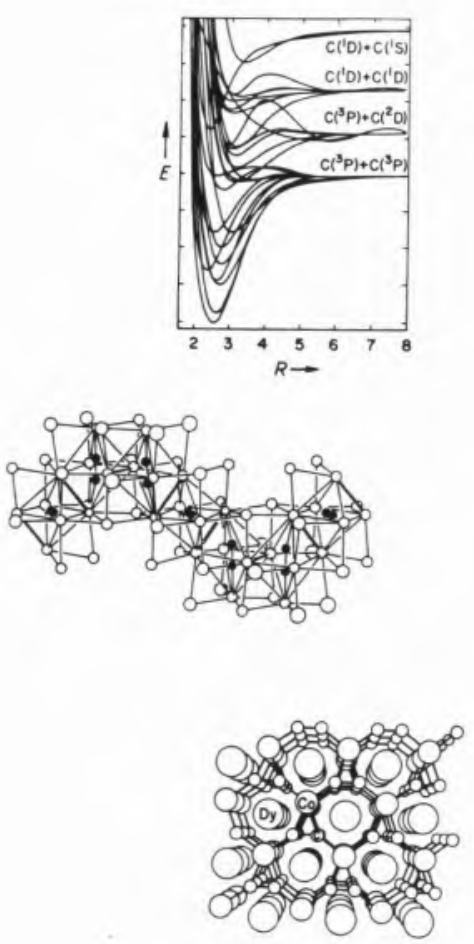

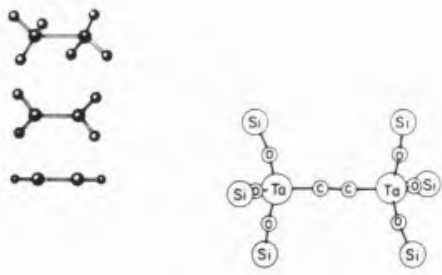

$\mathrm{C}_{2}$
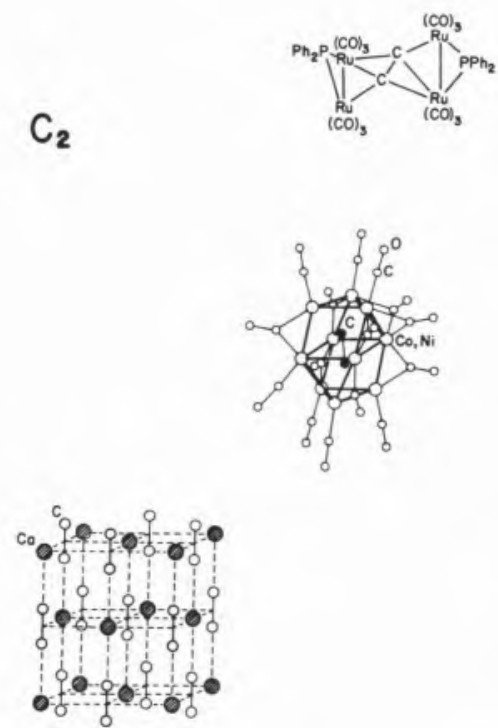

Vejo-o nos belos complexos moleculares de P. Wolczanski, [29b] M. I. Bruce, [29c] e G. Longoni [29d] e seus colaboradores, como se vê na Figura 3. Vejo-0 no $\mathrm{CaC}_{2}$ nos carbonetos de terras raras de W. Jeitschko [29e] e A. Simon [29f] e seus colaboradores. É espantoso!

Sei que esta riqueza foi criada por seres humanos. Por isso entristece-me ver a sua humanidade suprimida na maneira como se exprimem por escrito. Acho que há alguns perigos reais na atitude intelectual dos cientistas actuais e no seu modo ritual de comunicação.

São estes os perigos, tal como os vejo. A aceitação fácil duma filosofia reducionista, um modo vertical de compreensão tomado como o único modo de compreensão, criam um hiato entre nós e os nossos amigos das artes e letras. Eles sabem que não há só uma maneira de "comprensão" ou de lidar com a morte de um parente, uma eleição política, ou uma gravura em madeira de Ernst Ludwig Kirchner. 0 mundo lá fora é avesso ao reducionismo e, se insistimos que tem de ser redutível, só nos estamos a pôr numa caixa muito bonita. A caixa é a pequena classe de problemas que pode ser compreendida por um processo reducionista.

Um segundo perigo, mais específico, para 0 artigo científico, é que ao desumanizar o nosso modo de comunicação, tirando ele a emoção, a motivação, alguma irracionalidade, corremos 0 risco de fazer mais do que expulsar os Filósofos Naturais. Com certeza que 0 fizémos. Mas, ao fim de 150 anos nessa linha, o que criámos foi um produto mecânico, ritualizado, que propaga $3 \times 10^{5}$ vezes por ano a ideia de que os cientistas são secos e insensíveis, que só respondem a pequenas ondas dum espectro. 0 público em geral julga-nos pela natureza do nosso produto. Como pode fazer outra coisa, se nós nem nos esforçamos 0 suficiente para Ihe explicar 0 que fazemos, neste nosso mundo barricado com calão?

Que fazer? Eu seria por uma humanização geral do processo de publicação. Deixem-nos relaxar aquelas regras estritas, editoriais ou auto-impostas, e descrever por palavras, num artigo científico primário, a motivação, pessoal ou científica, a emoção, a historicidade, talvez alguma da irracionalidade. E se ocupar mais umas páginas? Podemonos manter a par da literatura química $\mathrm{e}$, da maneira que as coisas são, distinguir, sem muito esforço, a massa de trabalho 
amorfo do que é realmente inovador. As palavras humanizadoras não vos vão desviar; podem até encorajar-nos a ler com mais cuidado a substância do que é dito. Eu intercedia por uma valorização e ensino do estilo, na língua escrita e falada, tanto na do país de cada um, como no inglês. Acho que a Química tem muito a ganhar se se puder reviver o fundo pessoal, emocional e estilístico, da luta que conduz à descoberta e criação do mundo molecular.

\section{REFERÊNCIAS}

1. A Angewandte Chemie tem sido muito importante para mim e é um prazer dedicar esta conferência ao corpo editorial, passado e presente, duma das melhores revistas do mundo.

2. E. Garfield: Essays of an Information Scientist, ISI Press, Philadelphia, 1981, pg. 394400 e referências ai citadas.

3. a) S. Shapin, Social Stud. Sci. 14 (1984) 487; b) P. Dear, Isis 76 (1985) 145; c) F.L. Holmes in P. Dear (Ed.): the Paper Laboratory, University of Pennsylvania Press, Philadelphia, em publicação.

4. F. Goldmann, Ber. Dtsch. Chem. Ges. 21 (1888) 1176.

5. Para uma discussão sobre a evolução da escrita cientifica ver B. Coleman, New York Times Book Review, September 27, 1987, pg. 1; também R. Wallsgrove, New. Sci. $116(1987) n^{\circ}$ 24. pg. 55 .

6. 0. J. Scherer, T. Brück, Angew. Chem. 99 (1987) 59; Angew. Chem. Int. Ed. Engl. 26 (1987) 59.

7. A versão aqui apresentada é a inglesa. $A$ Angewandte Chemie é única ao imprimir (desde 1963) o mesmo artigo em versōes inglesa e alemã.

8. Para uma demonstração da gama de atitudes cerca do que é a Ciência, ver a discussão nas páginas da Nature (330 (1987)308, 689; 331 (1988) 129, 558) na sequência de um artigo de T. Teocharis e M. Psimopoulos (Nature 329 (1987) 595).

9. A frase usada é de J. Ziman: Reliable Knowledge, Cambridge University Press, Cambridge, Inglaterra 1987. Discordo de alguns pontos deste livro, mas não há nenhuma descrição melhor e mais humanistica sobre o que é e deveria ser a Ciência do que este pequeno volume.

10. M. Berthelot: Chimie Organique Fondée sur la Synthèse, Tome 2, Mallet-Bachelier, Paris 1860. Ver também J.-P. Malrieu, L'Actualité Chimique 1987, n³, pg. IX; A. F. Bochkov, V. A.
Smit: Organicheskii Sintez (Organic Synthesis), Nauka, Moscovo 1987; e um ensaio 'Em Louvor da Sintese" por R. Hoffmann, publicado em Química-Boletim da Sociedade Portuguesa de Química, 49 (1993) 28.

11. Para diferentes visōes do modo como a Ciência opera, ver: a) P. Feyerabend: Against Method, NLB, Londres 1975; Wider den Methodenzwang, Suhrkamp, Frankfurt am Main 1976; b) B. Latour, S. Woolgar: Laboratory Life, Princeton University, Princeton 1986; c) K. Knorr-Cetina: Die Fabrikation von Erkenntnis, Suhrkamp, Frankfurt am Main, 1984.

12. Fui lembrado da importância da distinção indivíduo-sistema por uma conversa com Barry Carpenter. Estou-Ihe grato por uma discussão das questōes levantadas por este ensaio, bem como a outro colega, Bruce Ganem, pelos seus comentários.

13. Devem-se distinguir vários tipos de reducionismo. Ver o interessante debate entre S Weinberg (Nature 330 (1987) 443; 331 (1988) 475) e E. Mayr (Nature 331 (1988) 475 e referências aí citadas)

14. Ver, entre outros, K. Mislow, P. Bickart, Israel J. Chem. 15 (1976/77) 1; D. W. Theobald. Chem. Soc. Rev. 5 (1976) 203.

15. R. G. Bergman, numa conferência não publicada sobre "Values in Science", cita alguns dados não tratados, fascinantes, sobre este problema, obtidos da sua experiência nas revistas Organic Synthesis e Inorganic Synthesis.

16. Latour e Woolgar ([11b], pg. 183) são muito desdenhosos em relação a este tipo de embevecimento com a verificabilidade e reprodutibilidade dos factos científicos a que aludo aqui. Acho que foram apanhados na ideologia consistentemente inquiridora e céptica da sua investigação antropológica, de outro modo incisiva, sobre como são construídos os factos científicos. Deviam dar uma olhadela à produção industrial, sistemática, espalhada por todo 0 mundo, de produtos farmacêuticos, só para dar um exemplo duma actividade experimental reprodutivel 17. D. Locke: Science as Writing, a ser publicado.

18. J. Derrida no seu ensaio "Signature Event Contest" em Marges de la Philosophie, Editions Minuit, Paris 1972, pg. 365-393; tradução (por A. Bass): Margins of Philosophy, University of Chicago Press, Chicago 1982, pg. 307-330.

19. L. F. Fieser, M. Fieser: Style Guide for Chemists, Reinhold, New York 1960, pg. 51-52. 20. P. B. Medawar, Saturday Review, August 1. 1964, pg. 42, também defende que o formato convencional do artigo científico representa mal os processos do pensamento que participam na descoberta.

21. Ver R. Hoffmann, Am. Sci. 75 (1987) 619; 76 (1988) 182

22. Para uma introdução às teorias literárias modernas, ver T. Eagleton: Literary Theory,
University of Minnesota Press, Minneapolis 1983.

23. C. F. von Weizsäcker: Die Einheit der Natur, dtv, Munique 1974, pg. 61-83.

24. Para uma descrição do processamento da informação geométrica e topológica que tem lugar na Química Orgânica, ver também N. J. Turro, Angew. Chem. 98 (1986) 872; Angew. Chem. Int. Ed. Engl. 25 (1986) 882.

25. Pierre Laszlo escreveu um artigo esclarecedor sobre a ilustração técnica ("The Pictures of Science") que é relevante para a minha discussão. Uma versão francesa deste artigo ("Science en Images") foi aceite para publicação em ECA$L E, N^{\circ} 2$, publicada por Ecole Cantonale d'Art, Lausana.

26. M. Pique, J. S. Richardson, F. P. Brooks, Jr., Invited Videotape, 1982 SIGGRAPH Conference. Estou grato a J. S. Lipscomb por me dar a ver este video.

27. P. B. Medawar diz, segundo as mesmas linhas, que "... os cientistas não deviam ter vergonha de admitir... que aparecem hipóteses no seu pensamento por caminhos travessos..." (ver [20]).

28. H. Weinrich, Merkur 39 (1985) № 436 , p. 469. Estou grato a P. Gölitz por chamar a minha atenção para este artigo.

29. a) As curvas de energia potencial do $C_{2}$ foram adaptadas de P. P. Fougere e R. K. Nesbet (J. Chem. Phys. 44 (1966) 285); b) [i( $\left.\left.t \mathrm{Bu}_{3} \mathrm{SiO}_{3}\right)_{3} \mathrm{Ta}_{2} \mathrm{C}_{2}\right]:$ R. E. LaPointe, P. T. Wolczanski, J. F. Mitchell, J. Am. Chem. Soc. 108 (1986) 6382; c) $\left[\mathrm{Ru}_{4} \mathrm{C}_{2}\left(\mathrm{PPh}_{2}\right)_{2}(\mathrm{CO})_{12}\right]: \mathrm{M}$. I. Bruce, M. R. Snow, E. R. T. Tiekink, M. L. Williams, J. Chem. Soc. Chem. Comm. (1986) 701 ; d) $\left[\mathrm{CO}_{3} \mathrm{Ni}_{7} \mathrm{C}_{2}(\mathrm{CO})_{15}\right]^{3-}:$ G. Longoni, A. Ceriotti, R. Della Pergola, M. Manassero, M. Perego, G. Piro, M. Sansoni, Phil. Trans, R. Soc., London, Sr. A308 (1982) 47; e) DyCoC $_{2}$ : W. Jeitschko, M. H. Gerss, J. Less Common Met. 116 (1986) 147; f) $\mathrm{Gd}_{12} \mathrm{C}_{6} \mathrm{I}_{7}$ : A. Simon, E. Warkentin, Z. Anorg. Allg. Chem. 497 (1983) 79

Tradução de "Under the Surface of the Chemical Article", Angewandte Chemie Int. Ed. Engl. 27 (1988) 1593 por M. J. C., com a autorização do autor e do editor.

* Este artigo deriva do texto duma conferência apresentada no Chemiedozententagung em Mainz, a 14 de Março de 1988. Celebrava-se, numa sessão especial, $0100^{\circ}$ aniversário da Angewandte Chemie

**R. Hoffmann é professor de Química na Universidade de Cornell, Nova Iorque, Estados Unidos da América 


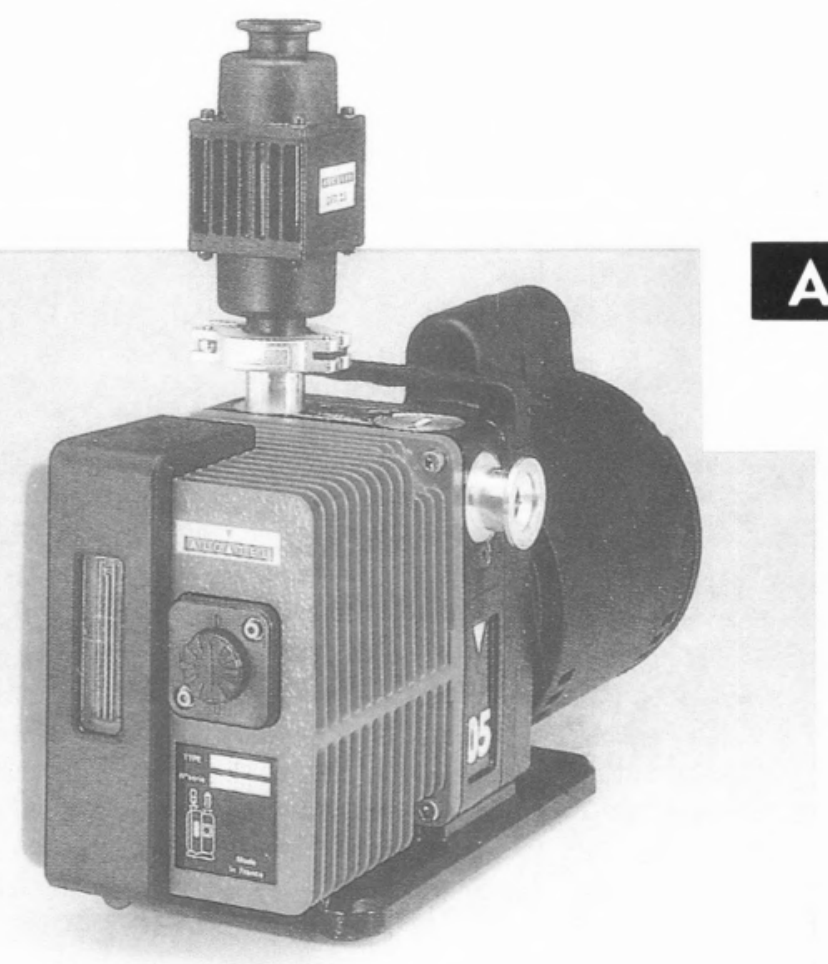

\author{
INFORME-SE SOBRE AS \\ NOVAS ROTATÓRIAS \\ PASCAL \\ DA ALCATEL.
UM DIA TODAS AS ROTATÓRIAS SERÃO ASSIM...

EM QUALQUER POSIÇÃO

27.000 r. p. $\mathrm{m}$. apenas

O QUE NOS PERMITE FAZER LOCALMENTE, TOTAL SERVIÇOE MANUTENÇÃOO

VERIFIQUE QUE $90 \%$ DO EQUIPAMENTO DE. VÁCUO, EM PORTUGAL, DESDE 1991, É ALCATEL

\title{
_ ERIOLA日 \\ PRACA D. AFONSO V, 120 4100 PORTO (PORTUGAL) TELEFONE 682029 FAX, 6102406
}

